\title{
Biofilm Associated Infection and its Novel Therapeutics Strategy
}

\author{
Namita Shukla*, Rajesh Kumar, Jubeda Begum and Garima Pandey \\ College of Veterinary and Animal Sciences, G.B.P.U.A.T., Pantnagar India \\ *Corresponding author
}

\section{Keywords}

Biofilm, Dispersion, Quorum sensing, Antimicrobial peptides, Nanotechnology

Article Info

Accepted:

10 January 2021

Available Online:

10 February 2021

\section{A B S T R A C T}

A biofilm is complex communities of bacteria attached to a surface or interface enclosed in an exopolysaccharide matrix and protected from unfavourable conditions such as presence of antibiotics, host defence or oxidative stresses. Biofilms are often considered hot spot for horizontal gene transfer among same or different bacterial species. Furthermore, bacteria with increased hydrophobicity facilitate biofilm formation by reducing repulsion between the extracellular matrix and the bacterium. Cells within a biofilm have intrinsic characteristics that are different from those of planktonic cells. Biofilm resistance to antimicrobial agents has drawn increasing attention. It is well-known that medical deviceand tissue-associated biofilms may be the leading cause for the failure of antibiotic treatments and can cause many chronic infections. Since microorganisms growing in a biofilm are highly resistant to antimicrobial agents and host's immune system, it is necessary to employ effective methods for the prevention or control of biofilm formation. The key to success for biofilm prevention and control may hinge upon a more complete understanding of what makes the biofilm phenotype so different from the planktonic phenotype. Conventionally used antimicrobial agents have a restricted range of cellular targets and limited efficacy on biofilms. This emphasizes the need to explore the alternate therapeutical like anti-adhesion compounds, phytochemicals, nanomaterials for effective drug delivery to restrict the growth of biofilm

\section{Introduction}

A common misconception of microbial living is that bacteria exist as individual organisms in a 'planktonic state'. Rather, microorganisms have been shown to naturally accumulate on a wide variety of surfaces; where they form sessile, communities. Those surfaces include household and industrial pipes, biomaterials such as contact lenses, medical devices including implants and urinary catheters, as well as plant and animal tissues. These accumulations of microorganisms of mono- or poly-microbial aggregates are commonly referred to as a biofilm and can consist of diverse communities of microbes. In nature, microbes exist in two distinct forms, planktonicor sessile. Biofilms are communities of surfaceattached multicellular microorganisms, characterized by bacteria embedded in a selfgenerated matrix (Costerton et al., 1995). Throughout their evolution, bacteria have constantly modified their metabolism and 
physical characteristics, adapting to practically almost to all environments. Biofilm formation is a significant virulence mechanism in the pathogenesis of many important bacterial pathogens, such as Pseudomonas aeruginosa (Gellatly and Hancock, 2013), Staphylococcus aureus (Gordon and Lowy, 2008), and Escherichia coli (Beloin et al., 2008). Biofilm formation is a cooperative group behaviour that involves bacterial populations living embedded in a self-produced extracellular matrix. Biofilms may form on living or non-living surfaces and can be prevalent in natural, industrial, and hospital settings (Lear et al., 2012). In nature, microorganisms exist primarily by attaching to and growing upon biotic and abiotic surfaces. These surfaces may take many forms, including those found in soil and aquatic systems, those on the spectrum of indwelling medical devices, and those of living tissues such as tooth enamel, heart valves, or the lung, middle ear and chronic wound infection. The microbial cells growing in a biofilm have intrinsic characteristics that are different from those of planktonic Biofilm formation is a survival strategy microbes adopt to enable them survive unpredictable environmental stressors such as temperature changes, desiccation, ultraviolet radiation, cleansing agents such as biocides and disinfectant pressure as well as host immune systems. Due to the widespread distribution of biofilms in diseases and their resilience to numerous antimicrobial treatments, biofilm research is receiving more attention. Owing to increasing antimicrobial resistance, the focus of current research is shifting from targeting bacterial growth/division that causes cell death or dormancy, towards novel therapeutic approaches. Bacteria in biofilm behave differently from planktonic bacteria, especially in terms of their response to antibiotic treatment (Donlan, 2001). Biofilms exist in various infections and have been demonstrated to play an important role in animal and human diseases. Biofilms act as physical barriers against drugs and host immune responses, leading to resistance to antimicrobial treatment. Biofilms obviously reduce the possibility of eradicating infections and cause relapses after the traditional appropriate treatment. The onset of biofilmrelated infections can increase not only severe symptoms but also mortality (Tascini et al., 2018) A potential approach to combat biofilm-related infections, is to induce biofilm dispersion, as dispersed cells and remaining biofilm cells have been shown to be more susceptible (Kalpana 2010). Here, in the present review, several active and passive dispersion strategies biofilm associated infection and recent progress in alternative therapies and strategies against microbial biofilms are discussed.

\section{Biofilm, an important community behaviour of microbes}

The study of cooperation has preoccupied biologists for centuries but the potential for social behaviour in microbes has only recently been recognized. Established examples include collective hunting by Myxococcus (Velicer and Vos, 2009), aggregation and subsequent cell death in stalks of Dictyostelium (Bonner, 2009; Strassmann and Queller, 2011) and biofilm formation, such as in the mats of Pseudomonas fluorescens (Rainey and Rainey, 2003) or Bacillus subtilis (van Gestel et al., 2014). In nature, microbes exist in two distinct forms, planktonic or sessile. Sessile microbial communities attached to a surface often develop a complex structure called a biofilm because it looks like a thin layer covering the surface. We now understand that biofilms are emblematic of the sessile form of microbes, in which microbial cells adhere to surfaces as well-structured microcolonies surrounded by a complex matrix composed of many extracellular polymeric substances 
(EPS). EPSs are building materials for biofilm architecture and include polysaccharides, extracellular DNAs (eDNA), and proteins that function as the matrix of the biofilm and as a glue holding the biofilm to the surface (Wei and Ma, 2013). EPSs are normally selfproduced by microbes along with, these matrices may also contain material from the surrounding environment. Actually, microbial biofilms are similar to our civilized towns in that individuals live together as a community in architectures built with materials prepared by them. Biofilms have been described as "microbial cities" with a complex mixture of ethnic neighbourhoods, transportation and communication networks, protection mechanisms for inhabitants, and controls of population and mass (Watnick and Kolter, 2000). Social behaviour simply means a behaviour that affects another cell's evolutionary fitness (Hamilton 1964, Wilson 1975), and the most interesting social behaviours are the ones that evolved because they affect others (West et al., 2007). Biofilms are often considered an example of microbial social behavior because many studies have revealed that cells communicate with each other during biofilm formation (Landini et al., 2010; Shrout et al., 2011). As a social behaviour, complex development and differentiation occur in biofilms according to the growth stages of biofilm that are influenced by a variety of environmental cues and cell-to-cell signaling that trigger specific molecular events within a cell.. As a social behavior, complex development and differentiation occur in biofilms according to the growth stages of biofilm that are influenced by a variety of environmental cues and cell-to-cell signaling that trigger specific molecular events within a cell. Quorum sensing (QS) has been studied as a representative signaling mechanism that enables bacterial cells to communicate with each other. The term 'bioflm' was frst used to describe this predominant form of bacterial life in environmental microbiology in 1935 , and from 1985 it became commonplace in medical microbiology (Høiby 2014). Although 'bioflm' is recent in name, it is the oldest life-form on Earth (Bowler.2018), and it has recently been reported that bioflms dominate all habitats on the Earth's surface, accounting for up to $80 \%$ of the approximate $1.2 \times 1030$ bacterial cell population (Flemming et al., 2019). Biofilms are complex communities of microorganisms adhering to a either biotic or abiotic surface and encased in a protective exopolymeric substance. Biofilm formation is commonly to occur in five main stages. In first stage, individual planktonic cells migrate and adhere to a surface. When suitable conditions are present, these adherent cells then initiate biofilm production on the surface and become encased in small quantities of exopolymeric material. In second stage, adherent cells secrete an extracellular polymeric substance (EPS) and become irreversibly attached to the surface, which results in cell aggregation and matrix formation. In third stage, the biofilm begins to mature by developing microcolonies and water channel architecture, while also becoming significantly more layered. In fourth stage, the fully mature biofilm reaches its maximum cell density and is now considered a three-dimensional community. In fifth stage, the mature biofilm releases microcolonies of cells from the main community, which are free to migrate to new surfaces spreading the infection to other locations (Stoodley et al., 2002; Schachter, 2003) The extracellular matrix encasing the cells in a biofilm, also referred to as the EPS, is composed of a complex mixture of proteins, lipids, nucleic acids (extracellularDNA), and polysaccharides (Annous et al., 2009). These constituents not only assist in securing the biofilm to the surface, but also trap nutrients, provide structural support, and shield against host immune responses and antimicrobial treatments (Flemming et al., 
2007). In addition to the above functions, the EPS is also responsible for holding the community of biofilm cells in close proximity, thereby enabling cell-to-cell communication (quorum sensing), and facilitating the exchange of genetic material through horizontal gene transfer (Hausner and Wuertz, 1999). At the early stage of biofilm study, QS was the most examined signaling mechanism required for biofilm formation, but our current knowledge expands to more comprehensive signalling networks working together to regulate biofilm formation and development.

The two-component systems regulate the switch from a planktonic to a sessile mode of bacterial life either via the production of extracellular appendages or by the production of exopolysaccharides in response to diverse environmental stimuli (Mikkelsen et al., 2011). Communication between neighbouring bacteria via quorum sensing is a social behaviour that enables interactions within mono and mixed bacterial communities. Quorum sensing requires production and release of chemical signal molecules called autoinducers that increase in concentration as a function of cell density but can also depend upon physiological conditions ( $\mathrm{Ng} \&$ Bassler, 2009).

\section{Prevalence and Importance of Biofilms in Animals and Humans}

Biofilms may form on a wide variety of surfaces, including natural aquatic systems biotic tissues, indwelling medical devices and industrial/potable water system piping. Biofilm formation is a phenomenon that occurs in both natural and man-made environments. Biofilms may exist as beneficial epithilic communities in rivers and streams, wastewater treatment plant trickling beds or in the alimentary canal of mammals (Costerton et al., 1981). Biofilms are not, only confined to solid/liquid interfaces, but also be found at solid/air or liquid/liquid interfaces. In humans, an estimated $65 \%$ of all hospital infections are of biofilm origin(Ramage et al., 2006) Once established, biofilm infections are very difficult to eradicate due to their resilience to removal by host defence mechanisms and antimicrobials.Biofilms may be composed of a single bacterial species e.g., Vibrio cholerae, (Teschler et al., 2015) but more frequently they are formed by a complex and diverse community of microorganisms (bacteria, algae, fungi and protozoa) embedded in an extracellular matrix of polysaccharides, exudates, and detritus (Costerton et al., 1978; Wimpenny et al., 2000). Many microbial species are able to change their lifestyle (free-living vs. attached) depending on their physiological status and the physicochemical conditions in their surroundings, taking advantage of the greater availability of organic matter in suspended particles and surfaces (Simon et al., 2002; Grossart, 2010; Teschler et al., 2015).

In aquatic habitats, biofilms develop not only in benthic substrata, such as streambed cobbles and sand, but also on floating macroand microaggregates (Simon et al., 2002). From an ecological perspective, microorganisms in environmental biofilms actively participate in organic matter decomposition, nutrient dynamics and biogeochemical cycling, being a key component of ecosystem functioning (Romaní, 2010)Biofilms are not exclusively laboratory phenomena, nor are they found only in habitats altered by human and animal interference such as polluted streams, ships hulls and urinary catheters. Biofilms also form in primitive natural habitats such as this alpine lake. Biofilm communities are ubiquitous. They are found in every habitat in which water, nutrients, and a surface are found. From the frozen deserts of the Antarctic, to the depths of the ocean. 


\section{Biofilm dispersion}

Biofilm dispersion has become widely recognized as a natural phenomenon associated with the terminal stage of biofilm development. Pronounced advances have been made in the understanding of the mechanisms of dispersal in various bacterial species Biofilm dispersion is also important as a potential control point for the manipulation of biofilm development and persistence. Dispersal of cells from the biofilm colony is an essential stage of the biofilm life cycle. Dispersal enables biofilms to spread and colonize new surfaces. Enzymes that degrade the biofilm extracellular matrix, such as dispersin B and deoxyribonuclease, may contribute to biofilm dispersal. Enzymes that degrade the biofilm matrix may be useful as anti-biofilm agents There are two mechanism of biofilm dispersion depending on the trigger, can be distinguished into two broad categories: active and passive (Kaplan 2010). Active dispersal refers to mechanisms that are initiated by the bacteria themselves, whereas passive dispersal refers to biofilm cell detachment that is mediated by external forces such as fluid shear, abrasion (collision of solid particles with the biofilm), predator grazing, and human intervention (Lawrence et al., 2002; Choi and Morgenroth, 2003; Ymele-Leki and Ross, 2007). There are three distinct modes of biofilm dispersal have been identified: erosion, sloughing, and seeding. Erosion refers to the continuous release of single cells or small clusters of cells from a biofilm at low levels over the course of biofilm formation. Sloughing refers to the sudden detachment of large portions of the biofilm, usually during the later stages of biofilm formation (Marshall, 1988; LappinScott and Bass, 2001; Stoodley et al., 2001; Wilson et al., 2004). Seeding dispersal, also known as central hollowing, refers to the rapid release of a large number of single cells or small clusters of cells from hollow cavities that form inside the biofilm colony (Boles $e t$ al., 2005; Ma et al., 2009). Erosion and sloughing can be either active or passive processes, whereas seeding dispersal is always an active process.

\section{Active biofilm dispersion}

Active biofilm dispersion is induced by an environmental change. These changes can be a sudden increase or decrease in the concentration of a carbon source, an increase in the concentration of the nitrogen source, oxygen depletion, elevated levels of nitric oxide (NO), or increased heavy metal concentrations(Roy et al., 2012)

C-di-GMP is a main regulatory component in biofilm dispersion (Romling et al., 2013). Low intracellular c-di-GMP concentrations promote the planktonic lifestyle, while high concentrations stimulate life as a biofilm (Romling et al., 2013). The c-di-GMP concentration is regulated by diguanylate cyclases (DGCs) and PDEs [18]. During active biofilm dispersion, the dispersion trigger leads to c-di-GMP hydrolysis by PDEs (Kaplan, 2010; Petrova et al., 2016; Romling et al., 2013). This decrease in c-di-GMP concentration activates the expression of genes involved in motility and genes involved in matrix degradation (Petrova et al., 2016). One of the first molecules that were identified as a biofilm dispersing agent was Nitric oxide (NO). NO is produced by macrophages in order to kill bacteria like Mycobacterium tuberculosis and Salmonella typhimurium. NO activates PDEs which results in the decrease of the c-di-GMP concentration. The NOdonor sodium nitroprusside (SNP) has been sketch to induce Pseudomonas aeruginosa biofilm dispersion. The biofilm remaining after NO induced dispersion is more susceptible to an antibiotic treatment than the original non-dispersed the effect of $\mathrm{NO}$ on biofilms is mostly studied in $P$. aeruginosa, 
however, it also induces dispersion of biofilms formed by other species as well. Fluctuations in nutrient concentrations have been shown to induce biofilm dispersion. Besides a sudden increase of nutrients, nutrient depletion also induces biofilm dispersion in vitro. Heavy metals also actively induce dispersion. The biofilm matrix is composed out of three building-blocks: extracellular polysaccharides, DNA and proteins. The EPS-degrading enzymes can cause the dispersion by destroying and modifying the biofilm matrix The effector enzymes for matrix destruction include DNases, polysaccharide-degrading enzymes, proteases, and so on (Kaplan, 2010) During active dispersion, biofilm cells produce enzymes that degrade the matrix(Kaplan. 2010). Matrix-degrading enzymes implicated in active biofilm dispersal include glycosidases, proteases, and deoxyribonucleases. Dispersin B breaks the 1 $\rightarrow 4$ glycosidic bonds of $\beta$-substituted $N$ acetylglucosamine. One well-studied biofilmmatrix-degrading enzyme is dispersin $\mathrm{B}$, a glycoside hydrolase produced by the period on to pathogen $A$. actinomycetemcomitans (Kaplan et al., 2003b)

\section{Passive biofilm dispersion}

Passive dispersion refers to the direct removal of cells from the biofilm, independent from bacterial responses. During passive dispersal, the dispersion trigger directly leads to the removal of the biofilm cells, i.e. independent from the c-di-GMP concentration Several physical triggers such as erosion, sloughing, collisions with particles, and grazing can lead to passive biofilm dispersal. In 1988, Breyers proposed four mechanisms of detachment that result in the release of cells from the biofilm: abrasion, shear-related removal and sloughing (Breyers.1988) during abrasion, the collision of particles with the biofilm, results in the release of cells or biofilm clumps
[Breyers.1988]. Shear-related removal is due to the continuous shear of a liquid over the biofilm which results in the erosion of single cells or aggregates from the biofilm [61]. Sloughing is the periodical release of biofilm clumps, independent from the fluid shear. Finally, grazing by eukaryotic organisms like protozoa also leads to biofilm detachment (Breyers, 1988). Along with these natural occurring passive modes of dispersion, several techniques have been developed to induce passive dispersion.

\section{The roles of biofilm in infections}

Biofilms are one of the most important health threats, causing nearly $80 \%$ of refractory nosocomial infections (Jamal et al., 2018). Biofilm related infections can be divided into medical device- and tissue associated biofilm infections (Römling et al., 2014). Biofilm related infections can be divided into medical device- and tissue associated biofilm infections (Römling et al., 2014). With medical improvements, medical devices are widely used for treatments in clinical work. Urinary catheter-associated biofilms were observed in 1985, and antibiotic resistance of the biofilm was reported (Nickel et al., 1985). Biofilm formation on urinary catheters occurs mainly by one of two routes: Microorganisms may colonize the outer surface of the catheter. Microorganisms can also enter the urinary tract and form a catheter-associated biofilm through a bloodstream infection. Biofilms are associated with contact lenses, orthodontal prosthetics, endotracheal tubes, needleless connectors, central venous catheters, intrauterine devices, cardiovascular valves, pacemakers, prosthetic joints, and breast implants (Zahran et al., 2015; Sampaio et al., 2016; Gominet et al., 2017; Okuda et al., 2018; Stewart and Bjarnsholt, 2020; Walker et al., 2020). Many microorganisms can colonize and form biofilms in endotracheal tubes. Biofilms in endotracheal tubes are 
linked to ventilator-associated pneumonia, one of the most common infections and prominent causes of death in intensive care units (Orhan-Sungur and Akça, 2006; Fernández-Barat and Torres, 2016). Biofilm formation on long-term medical implants, such as prosthetic joints, pacemakers, heart valves, contact lenses, and breast implants, leads to major postoperative complications. Infections can cause inflammation and tissue destruction around implants, and sometimes, these infections are life threatening. Medicaldevice-associated biofilms are the most important sources of nosocomial infections. Most of the pathogens associated with device are multidrug resistant, and the treatment of these biofilms is very challenging.

Microorganisms may also adhere to biotic surfaces and form biofilms in different tissues in the host, e.g., epidermal cells (Paranjpye and Strom, 2005) and teeth (Black et al., 2004), or they may be located in tissues, e.g., in the mucus on mucosal membranes (Cellini et al., 2008) or inside chronic wounds (Akiyama et al., 1996). It has been identified that multiple gastrointestinal infections can be caused by biofilm formation. Biofilm formation on human gastric mucosa by Helicobacter pylori has been observed in endoscopically directed biopsies with scanning electron microscopy (Carron et al., 2006). Salmonella can form biofilms on human gallstones, and bile can significantly enhance the biofilm formation of Salmonella. The biofilm of Salmonella on gallstones may be a source of chronic infection and is related to a high risk for developing gallbladder cancer (Prouty et al., 2002). Multiple microbes, such as E. coli (Conway and Cohen, 2015), V. cholerae (Silva and Benitez, 2016), and S. enterica (Azriel et al., 2015), can form biofilms in host intestines. Probiotics, which are live bacteria and yeasts used in the treatment and prevention of diarrheal diseases and help keep the gut healthy, can also form biofilms (SlíŽová et al., 2015). Biofilm formation of commensal/probiotic-type strains can confer an expedience, shield the host against pathogens and reducing the incidence and severity of enterocolitis (Olson et al., 2016).

The importance of biofilm in disease processes in humans and animals is now widely recognized. In animal species, the risk of infection is probably greater than the risk in humans. This is due to the difference in animal housing and living environments (Zambori et al., 2012). In dogs and cats mouth normal bacterial microflora is systematised in a variety of aerobic, facultative or strictly anaerobic bacteria. In the oral cavity, teeth provide constant humidity and adherent surfaces causing the attachment of extensive deposits of microorganisms (Pavlica, 2006).

\section{Novel therapeutics strategy against Biofilm}

Various physical, chemical and biological agents are being investigated for their effectiveness for in controlling biofilm both in in vivo and in vitro. For formulating effective biofilm control methodology better understanding of antibiofilm agent are required, as many common antimicrobial agents are effective against planktonic bacteria but are only partially or totally ineffective against the same bacteria in biofilm. It is difficult to control the biofilm development because microorganisms in biofilm evolve different mechanisms in different environment; however, there are recent progress in alternative therapies and strategies against microbial biofilms

\section{Conventional antibiotic combination treatments}

Microbes inside biofilm require much higher minimum inhibitory concentration of 
antibiotic and it is provided by tropical application (Olivares et al., 2020). Despite the intensive tolerance of the biofilm to antimicrobials, certain conventional antibiotics still demonstrate activity against bacterial cells growing in the biofilm state. In a recent study, Otani et al., (2018) showed that sub-MICs of ceftazidime reduce biofilm volume, inhibit twitching motility, and repress gene expression involved in bacterial adhesion and matrix production of $\mathrm{P}$. aeruginosa PAO1.

In a recent article, Klinger-Strobel et al., (2017) noticed that colistin concentrations from 4 to $16 \mathrm{mg} / \mathrm{l}$ could reduce the amount of adherent E. coli bacteria and exert a matrixreducing effect on biofilms in formation. Similarly, Butini et al., (2018) investigated the anti-biofilm property of gentamicineluting bone graft substitute against bacterial species involved in bone and implantassociated infections. Because of the resistance of biofilms to antibiotic treatments, combination therapy with different medicines was considered to try to eradicate biofilms. In an initial attempt, an E. coli biofilm was treated with a combination of the antibiotics amdinocillin and cefamandole in 1987 (Prosser et al., 1987). Researchers continue to try various combination schemes to eliminate biofilms through synergistic effects and are also trying sequential/alternate therapies and high-dose topical treatments (Akturk et al., 2019). Many combination antibiotic therapy fetch have been used in clinical case studies (Dales et al., 2009). The synergism of antibiotics and other kinds of medicine has also been recognised, such as that of sodium salicylate and $\mathrm{N}$-acetylcysteine (Polonio et al., 2001; Belfield et al., 2017). However, biofilms can be difficult to thoroughly remove because the dose of antibiotics is limited by their side effects (Ciofu et al., 2017). Thus, considerable focus has been paid to new agents and technological developments

\section{Antimicrobial peptides}

AMPs are small evolutionally conserved molecules found in virtually every life form, from multicellular organisms to bacterial cells. AMPs are effector molecules of the innate immune system and have a broad antimicrobial spectrum. In the last few years, interest in biofilm treatment by AMPs has been increasing dramatically. A number of natural, semi-synthetic, and synthetic AMPs have been proven active against microbial biofilms. Lactoferrin is an abundant multifunctional iron-binding protein of the innate immune system found in several mammal fluids (especially in milk), which is known to exert a broad-spectrum antimicrobial activity against bacteria, fungi, protozoa, and viruses. An antibiofilm activity of lactoferrin and its derivatives was also described (Singh et al., 2002; Ammons et al., 2009). Some AMPs can electrostatically interact with the host cellular membrane and have been used in some anticancer research because of their antitumor activity (Zhou et al., 2018). Natural AMPs often have poor stability and proinflammatory effects; however, synthetic AMPs are designed to overcome these shortcomings of AMPs. cathelicidin peptide LL-37 presents very weak anti planktonic cell activity, while its antibiofilm activity is much higher (Overhage et al., 2008). Some bacteriocins produced by almost all groups of bacteria present antibacterial activities, such as colicins and microcins. Colicins, produced by E. coli, and other colicin-like bacteriocins, produced by a range of Gram-negative bacteria, such as $\mathrm{P}$. aeruginosa, kill bacteria closely related to the producing bacteria (Brown et al., 2012). colicins and colicin-like bacteriocins are highly effective at killing target strains growing in the biofilm state (Brown et al., 2012). The use of AMPs to contrast biofilm formation represents an attractive prophylactic and therapeutic approach, 
because of the nonspecific mechanisms of action, the low rate in inducing microbial resistance, and the ability to target even nongrowing or persister cells (Jorge et al., 2012).

\section{Surface modification}

The most common method for preventing bacterial adhesion is surface modification. The attachment of microorganisms to a surface is a critical step in biofilm development, and once biofilms develop on a medical surface, the eradication of biofilms becomes very difficult. Therefore, many studies have focused on modifying the surfaces of medical devices as a major strategy to eliminate biofilms. Here, the exterior surface of the implanted medical device or biomaterial is altered, either directly or with the aid of a coating, to produce a barrier which is inhospitable to bacteria (Bazaka et al., 2012). To combat biofilm formation, coatings for medical prostheses have been widely developed. Silver or silvercopper multilayer coatings used in various catheters and other medical devices, including urinary catheters, peritoneal catheters, vascular catheters, and fracture fixation devices, prevent the growth of biofilms (Bechert et al., 1999). Coating of the surfaces with antimicrobial agents reduce adhesion. Commercial coated catheters are coated with broad-spectrum antibiotics, such as chlorhexidine, minocycline, rifampin, and silver sulfadiazine, and these catheters have been used widely in clinical studies, especially in intensive care units. Hydrogels have been used to coat medical devices and have been shown to be effective in combating biofilms because of their good functional group density, biocompatibility, and lubricity (Norris et al., 2005).

Antifouling polyurethanes have been estimated to have antibiofilm activity and may be utilized as coating materials for medical implants (Tunney and Gorman, 2002).

\section{Nanotechnology}

It is believed nanotechnology-based approaches will provide promising advancements to prevent drug-resistant biofilm infections of medical devices and biomaterials. Copper, gold, silver, titanium, and zinc are known to have antibacterial and antibiofilm properties, which offer alternatives to antibiotics without significantly increasing the risk of resistance development. It has been established that metal-based NPs have much better antimicrobial activities than their micro-sized counterparts (Jones et al., 2008). Various NMs, such as lipid (Rout et al., 2017), polymer (Landis et al., 2017), and metal NM (Besinis et al., 2014), have been produced. Metal NMs have become the core materials because of their non-toxic nature and essential inertness (Burygin et al., 2009). Nanotechnology can play various roles in combating biofilms, not only by directly killing or inhibiting microbes but also by carrying antibiotics or other agents with antibiofilm activity (Li et al., 2019). CuO NPs exhibit effective antimicrobial activity against various bacteria, but they have less antibacterial activity than silver or zinc NPs, and hence higher concentrations are required to achieve desired antimicrobial effects, and at these concentrations $\mathrm{CuO}$ NPs could be toxic to mammalian cells (Ren et al.,2009) Gold NPs alone have little or no antibacterial activity. The main nanocarrier types include molecular complexes (such as protein nanocomplexes and cyclodextrin nanocomplexes), polymer-based nano capsules [such as dendrimers, core-shell nano capsules, and ligand decorated nanoparticles (NPs)], inorganic nanocarriers (such as metal NPs), and lipid-based nanovesicles (such as 
liposomes and solid lipid NPs). Toxicological tests of NPs are limited, and further longterm studies for risk assessment of NPs are needed.

\section{Enzymes for biofilm removal and that disperse extracellular polysaccharide substances of biofilms}

Enzymes targeting eDNA, extracellular polysaccharides, and proteins have been considered as strategies to eliminate biofilms (Kaplan et al., 2018). DNase I is effective in degrading eDNA in vitro and in vivo (Zhao et $a l ., 2018)$, and it was used to impair biofilms, reduce microbial adhesion, and induce the dispersal of pre-existing biofilms, especially early stage biofilms. Dispersin B, a new beta$\mathrm{N}$ acetylglucosaminidase functions as a promising antibiofilm agent (Kaplan et al., 2018); Dispersin B was used as one of the components in multilayer coatings and exhibited high antibiofilm efficiency with high stability (Pavlukhina et al., 2012). Researchers have also tried different enzyme combinations (Karygianni et al., 2020) or dispersal inducing enzymes combined with other new technologies, such as nanotechnology (Patel et al., 2019; Tasia et al., 2020), to improve antimicrobial biofilm activity and achieve good results.

\section{Antimicrobial photodynamic therapy}

Antimicrobial photodynamic therapy (aPDT) is a nonantibiotic broad-spectrum antimicrobial treatment that has been demonstrated to eradicate antibiotic-resistant bacteria and biofilms. aPDT is a two-step technique employing a photosensitizer (PS) that is first administered systemically or topically to a confined area, followed by illumination with a specific wavelength of light that can excite the PS to cause production of cytotoxic ROS in the presence of ambient molecular oxygen. The burst of ROS produced during illumination can exert lethal effects on both cancer cells and/or microbial pathogens. PDT was used as an antimicrobial strategy to inhibit biofilms formed by a broad spectrum of microbes). Subsequently, antimicrobial PDT was found to nonspecifically attack microorganisms by generating cytotoxic ROS, which have strong oxidation ability and high reactivity, thus causing rapid lipid oxidation of the bacteria (Qi et al., 2019). A majority of photosensitizers are poorly soluble in water and hydrophobic; however, with the application of NMs, this limitation might be overcome (Qi et al., 2019). In most of trials proved that PDT might become an antimicrobial therapy for biofilms, and no adverse effects of PDT were observed. Inspite of these more study are needed for drawing any conclusion.

In conclusions biofilms occur in almost any submerged surface in both natural and manmade systems providing a suitable and optimal environment for the growth, activity, and interaction of different bacterial species Most bacteria in nature exist in the form of biofilms. For the medical and veterinary profession, biofilms present a considerable challenge, as not only are they associated with most infections in humans and animal, but they are also extremely difficult to treat due to their inherent tolerance to immune responses and antimicrobials. Both active and passive biofilm dispersion are promising approaches as they reduce the biofilm biomass and increase the susceptibility of the remaining biofilm cells. Although the mechanisms of biofilm formation, growth, and antimicrobial resistance have been investigated by the research community, there is still a need for effective treatments against biofilmassociated organisms. Antibiotic therapy alone often fails to eradicate microbial biofilms. Many developments, such as AMPs and nanotechnology, have been made in recent years and have been identified as 
effective and promising. Some of these strategies have antibiofilm activities against multiple targets. By combining these promising agents with antibiotics, the eradication of biofilms may be possible in the future.

\section{References}

Akiyama, H., Kanzaki, H., Tada, J., and Arata, J. (1996). Staphylococcus aureus infection on cut wounds in the mouse skin: experimental staphylococcal botryomycosis. J. Dermatol. Sci. 11, 234-238.

Akturk, E., Oliveira, H., Santos, S. B., Costa, S., Kuyumcu, S., Melo, L. D. R., et al., (2019). Synergistic action of phage and antibiotics: parameters to enhance the killing efficacy against mono and dualspecies biofilms. Antibiotics (Basel). 8:103.

Ammons MCB Ward LS Fisher ST Wolcott $\mathrm{RD}$ James $\mathrm{GA}(2009)$ In vitro susceptibility of established biofilms composed of a clinical wound isolate of Pseudomonas aeruginosa treated with lactoferrin and xylitol. Int J Antimicrob Agents33: 230-236.

Annous, B. A., Fratamico, P. M., and Smith, J. L. (2009). Quorum sensing in biofilms: why bacteria behave the way they do. J. Food Sci. 74, R24-R37. doi: 10.1111/j.1750-3841.2008.01022.

Azriel, S., Goren, A., Rahav, G., and GalMor, O. (2015). The stringent response regulator DksA is required for Salmonella enterica serovar typhimurium growth in minimal medium, motility, biofilm formation, and intestinal colonization. Infect. Immun. 84, 375-384

Bazaka, K., Jacob, M. V., Crawford, R. J., and Ivanova, E. P. (2012). Efficient surface modification of biomaterial to prevent biofilm formation and the attachment of microorganisms. Appl. Microbiol. Biotechnol. 95, 299-311

Bechert, T., Böswald, M., Lugauer, S., Regenfus, A., Greil, J., and Guggenbichler, J. P. (1999). The Erlanger silver catheter: in vitro results for antimicrobial activity. Infection 27 (Suppl. 1), S24-S29

Belfield, K., Bayston, R., Hajduk, N., Levell, G., Birchall, J. P., and Daniel, M. (2017). Evaluation of combinations of putative anti-biofilm agents and antibiotics to eradicate biofilms of Staphylococcus aureus and Pseudomonas aeruginosa. J. Antimicrob. Chemother. 72, 25312538.

Beloin, C., Roux, A., and Ghigo, J. M. (2008). Escherichia coli biofilms. Curr. Top. Microbiol. 322, 249-289. doi: 10.1007/978-3-540-75418-3_12

Besinis, A., de Peralta, T., and Handy, R. D. (2014). Inhibition of biofilm formation and antibacterial properties of a silver nano-coating on human dentine. Nanotoxicology 8, 745-754

Black, C., Allan, I., Ford, S. K., Wilson, M., and McNab, R. (2004). Biofilm-specific surface properties and protein expression in oral Streptococcus sanguis. Arch. Oral Biol. 49, 295-304. doi: 10.1016/j.archoralbio.2003.12.001

Boles BR, Thoendel M, Singh PK (2005). Rhamnolipids mediate detachment of Pseudomonas aeruginosa from biofilms. Mol Microbiol 57:1210-1223.

Bonner, J. T. (2009). The Social Amoebae: The Biology of Cellular Slime Molds. Princeton, NJ: Princeton University Press.

Bowler PG. Antibiotic resistance and bioflm tolerance: a combined threat in the treatment of chronic infections. $\mathrm{J}$ Wound Care. 2018; 27(5): 273-7.

Breyers JD. Modeling biofilm accumulation. Physiol. Model. Microbiol., vol. II. 
CRC Press; 1988. p. 109-44.

Brown, C. L., Smith, K., McCaughey, L., and Walker, D. (2012). Colicinlike bacteriocins as novel therapeutic agents for the treatment of chronic biofilmmediated infection. Biochem. Soc. Trans. 40, 1549-1552.

Burygin, G. L., Khlebtsov, B. N., Shantrokha, A. N., Dykman, L. A., Bogatyrev, V. A., and Khlebtsov, N. G. (2009). On the enhanced antibacterial activity of antibiotics mixed with gold nanoparticles. Nanoscale Res. Lett. 4, 794-801.

Butini, M. E., Cabric, S., Trampuz, A., and Di Luca, M. (2018). In vitro antibiofilm activity of a biphasic gentamicin-loaded calcium sulfate/hydroxyapatite bone graft substitute. Colloids Surf. B Biointerfaces 161, 252-260.

Carron, M. A., Tran, V. R., Sugawa, C., and Coticchia, J. M. (2006). Identification of Helicobacter pylori biofilms in human gastric mucosa. J. Gastrointest. Surg. 10, 712-717

Cellini, L., Grande, R., Di Campli, E., Traini, T., Di Giulio, M., Lannutti, S. N., et al., (2008). Dynamic colonization of Helicobacter pylori in human gastric mucosa. Scand. J. Gastroenterol. 43, 178-185.

Choi YC, Morgenroth E (2003). Monitoring biofilm detachment under dynamic changes in shear stress using laserbased particle size analysis and mass fractionation. Water Sci Technol 47:6976.

Ciofu, O., Rojo-Molinero, E., Macià, M. D., and Oliver, A. (2017). Antibiotic treatment of biofilm infections. APMIS 125, 304-319

Conway, T., and Cohen, P. S. (2015). Commensal and pathogenic Escherichia coli metabolism in the Gut. Microbiol. Spectr. 3: 10.1128/microbiolspec.MBP0006- 2014.
Costerton JW, Irvin RT, Cheng KJ (1981) The bacterial glycocalyx in nature and disease. Annu Rev Microbiol 35:299324

Costerton, J. W., Geesey, G. G., and Cheng, K. J. (1978). How bacteria stick. Sci. Am. 238, 86-95. doi: 10.1038/scientificamerican0178-86

Costerton, J.W., Lewandowski, Z., Caldwell, D.E., Korber, D.R., and Lappin-Scott, H.M. (1995) Microbial biofilms. Annu Rev Microbiol 49: 711-745.

Dales, L., Ferris, W., Vandemheen, K., and Aaron, S. D. (2009). Combination antibiotic susceptibility of biofilmgrown Burkholderia cepacia and Pseudomonas aeruginosa isolated from patients with pulmonary exacerbations of cystic fibrosis. Eur. J. Clin. Microbiol. Infect. Dis. 28, 1275-1279

Donlan, R.M. 2001. Biofilms and deviceassociated infections. Emerg. Infect. Dis. 7:277-281.

Fernández-Barat, L., and Torres, A. (2016). Biofilms in ventilator-associated pneumonia. Future Microbiol. 11, 1599-1610. doi: 10.2217/fmb-20160040

Flemming H-C, Wuertz S. Bacteria and archaea on Earth and their abundance in bioflms. Nature Rev Microbiol. 2019; 17: 247-60.

Flemming, H.-C., Neu, T. R., and Wozniak, D. J. (2007). The EPS matrix: the "house of biofilm cells". J. Bacteriol. 189, 7945-7947. doi: 10.1128/JB.00858-07.

G. Ren, D. Hu, E. W. C. Cheng, M. A. Vargas-Reus, P. Reip, and R. P. Allaker, "Characterisation of copper oxide nanoparticles for antimicrobial applications," International Journal of Antimicrobial Agents, vol. 33, no. 6, pp. 587-590, 2009.

Gellatly, S. L., and Hancock, R. E. (2013). Pseudomonas aeruginosa: new insights 
into pathogenesis and host defenses. Pathog. Dis. 67, 159-173. doi: 10.1111/2049-632X.12033.

Gominet, M., Compain, F., Beloin, C., and Lebeaux, D. (2017). Central venous catheters and biofilms: where do we stand in 2017? APMIS 125, 365-375. doi: 10.1111/apm.12665

Gordon, R. J., and Lowy, F. D. (2008). Pathogenesis of methicillinresistant Staphylococcus aureus infection. Clin. Infect. Dis. 46, S350-S359. doi: 10.1086/533591.

Grossart, H. P. (2010). Ecological consequences of bacterioplankton lifestyles: changes in concepts are needed. Environ. Microbiol. Rep. 2, 706-714. doi: 10.1111/j.17582229.2010.00179.x

Hausner, M., and Wuertz, S. (1999). High rates of conjugation in bacterial biofilms as determined by quantitative in situ analysis. Appl. Environ. Microbiol. 65, 3710-3713.

Høiby N. A personal history of research on medical bioflms and bioflm infections. Pathogens Dis. 2014; 70: 205-11.

Jorge P Lourenço A Pereira MO (2012) New trends in peptide-based anti-biofilm strategies: a review of recent achievements and bioinformatic approaches. Biofouling28: 1033-1061.

Kaplan JB, Ragunath C, Ramasubbu N, Fine DH (2003b). Detachment of Actinobacillus actinomycetemcomitans biofilm cells by an endogenous $\beta$ hexosaminidase activity. J Bacteriol 185:4692-4698.

Kaplan JB. Biofilm dispersal: mechanisms, clinical implications, and potential therapeutic uses. J Dent Res 2010; 89:205-18. https://doi.org/10.1177/ 0022034509359403.

Kaplan JB. Biofilm dispersal: mechanisms, clinical implications, and potential therapeutic uses. J Dent Res
2010;89:205-18.

https://doi.org/10.1177/

0022034509359403.

Kaplan JB. Biofilm dispersal: mechanisms, clinical implications, and potential therapeutic uses. J Dent Res 2010; 89: 205-18.

Kaplan, J. B., Mlynek, K. D., Hettiarachchi, H., Alamneh, Y. A., Biggemann, L., Zurawski, D. V., et al., (2018). Extracellular polymeric substance (EPS)-degrading enzymes reduce staphylococcal surface attachment and biocide resistance on pig skin in vivo. PLoS ONE 13:e0205526.

Karygianni, L., Attin, T., and Thurnheer, T. (2020). Combined DNase and proteinase treatment interferes with composition and structural integrity of multispecies oral biofilms. J. Clin. Med. 9:983.

Klinger-Strobel, M., Stein, C., Forstner, C., Makarewicz, O., and Pletz, M. W. (2017). Effects of colistin on biofilm matrices of Escherichia coli and Staphylococcus aureus. Int. J. Antimicrob. Agents 49, 472-479.

Landini, P., Antoniani, D., Burgess, J.G., and Nijland, R. 2010. Molecular mechanisms of compounds affecting bacterial biofilm formation and dispersal. Appl. Microbiol. Biotechnol. 86, 813-823.

Landis, R. F., Gupta, A., Lee, Y. W., Wang, L. S., Golba, B., Couillaud, B., et al., (2017). Cross-linked polymer-stabilized nanocomposites for the treatment of bacterial biofilms. ACS Nano. 11, 946952.

Lappin-Scott HM, Bass C (2001). Biofilm formation: attachment, growth, and detachment of microbes from surfaces. Am J Infect Control 29:250-251.

Lawrence JR, Scharf B, Packroff G, Neu TR (2002). Microscale evaluation of the effects of grazing by invertebrates with 
contrasting feeding modes on river biofilm architecture and composition. Microb Ecol 44:199-207.

Lear G, Lewis GD, eds. (2012). Microbial Biofilms: Current Research and Applications. Caister Academic Press.

Li, X., Qi, M., Sun, X., Weir, M. D., Tay, F. R., Oates, T. W., et al., (2019). Surface treatments on titanium implants via nanostructured ceria for antibacterial and anti-inflammatory capabilities. Acta Biomater. 94, 627-643.

Ma L, Conover M, Lu H, Parsek MR, Bayles K, Wozniak DJ (2009). Assembly and development of the Pseudomonas aeruginosa biofilm matrix. PLoS Pathog 5:e1000354.

Marshall KC (1988). Adhesion and growth of bacteria at surfaces in oligotrophic habitats. Can J Microbiol 34:503-506.

Mikkelsen, H., Sivaneson, M., and Filloux, A. 2011. Key two-component regulatory systems that control biofilm formation in Pseudomonas aeruginosa. Environ. Microbiol. 13, 1666-1681.

N. Jones, B. Ray, K. T. Ranjit, and A. C. Manna, "Antibacterial activity of $\mathrm{ZnO}$ nanoparticle suspensions on a broad spectrum of microorganisms," FEMS Microbiology Letters, vol. 279, no. 1, pp. 71-76, 2008

$\mathrm{Ng}$ WL \&Bassler BL (2009)Bacterial quorum-sensing network architectures. Annu Rev Genet43: 197-222

Nickel, J. C., Ruseska, I., Wright, J. B., and Costerton, J. W. (1985). Tobramycin resistance of Pseudomonas aeruginosa cells growing as a biofilm on urinary catheter material. Antimicrob. Agents Chemother. 27, 619-624. doi: 10.1128/AAC.27.4.619.

Norris, P., Noble, M., Francolini, I., Vinogradov, A. M., Stewart, P. S., Ratner, B. D., et al., (2005). Ultrasonically controlled release of ciprofloxacin from self-assembled coatings on poly(2-hydroxyethyl methacrylate) hydrogels for Pseudomonas aeruginosa biofilm prevention. Antimicrob. Agents Chemother. 49, 4272-4279.

Okuda, K. I., Nagahori, R., Yamada, S., Sugimoto, S., Sato, C., Sato, M., et al., (2018). The composition and structure of biofilms developed by propionibacterium acnes isolated from cardiac pacemaker devices. Front. Microbiol. 9:182.

Olivares, E., Badel-Berchoux, S., Provot, C., Prévost, G., Bernardi, T., and Jehl, F. (2020). Clinical impact of antibiotics for the treatment of Pseudomonas aeruginosa biofilm infections. Front. Microbiol. 10:2894.

Olson, J. K., Rager, T. M., Navarro, J. B., Mashburn-Warren, L., Goodman, S. D., and Besner, G. E. (2016). Harvesting the benefits of biofilms: a novel probiotic delivery system for the prevention of necrotizing enterocolitis. J. Pediatr. Surg. 51, 936-941.

Orhan-Sungur, M., and Akça, O. (2006). Antiseptic impregnated endotracheal tubes, biofilms, and ventilatorassociated pneumonia. Crit. Care Med. 34, 2855-2857.

Otani, S., Hiramatsu, K., Hashinaga, K., Komiya, K., Umeki, K., Kishi, K., et al., (2018). Sub-minimum inhibitory concentrations of ceftazidime inhibit Pseudomonas aeruginosa biofilm formation. J. Infect. Chemother. 24, 428-433.

Overhage, J., Campisano, A., Bains, M., Torfs, E. C., Rehm, B. H., and Hancock, R. E. (2008). Human host defense peptide LL-37 prevents bacterial biofilm formation. Infect. Immun. 76, 4176-418.

Pakkulnan, R., Anutrakunchai, C., Kanthawong, S., Taweechaisupapong, S., Chareonsudjai, P., and 
Chareonsudjai, S. (2019). Extracellular DNA facilitates bacterial adhesion during Burkholderia pseudomallei biofilm formation. PLoS One. 14:e0213288

Paranjpye, R. N., and Strom, M. S. (2005). A vibrio vulnificus type IV pilin contributes to biofilm formation, adherence to epithelial cells, and virulence. Infect. Immun. 73, 14111422 .

Patel, K. K., Surekha, D. B., Tripathi, M., Anjum, M. M., Muthu, M. S., Tilak, R., et al., (2019). Antibiofilm potential of silver sulfadiazine loaded nanoparticle formulations: a study on the effect of DNase-I on microbial biofilm and wound healing activity. Mol. Pharm. 16, 3916-3925

Pavlica, Z. 2006. Biofilm, Microbial communities and periodontal disease, World Congress World Small Animal Veterinary Association.

Petrova OE, Sauer K. Escaping the biofilm in more than one way: desorption, detachment or dispersion. Curr Opin Microbiol 2016; 30:67-78. https://doi.org/ 10.1016/j.mib.2016.01.004

Polonio, R. E., Mermel, L. A., Paquette, G. E., and Sperry, J. F. (2001). Eradication of biofilm-forming Staphylococcus epidermidis (RP62A) by a combination of sodium salicylate and vancomycin. Antimicrob. Agents Chemother. 45, 3262-3266.

problem. FEMS Yeast Res 6:979-986

Prosser, B. L., Taylor, D., Dix, B. A., and Cleeland, R. (1987). Method of evaluating effects of antibiotics on bacterial biofilm. Antimicrob. Agents Chemother. 31, 1502-1506.

Prouty, A. M., Schwesinger, W. H., and Gunn, J. S. (2002). Biofilm formation and interaction with the surfaces of gallstones by Salmonella spp. Infect.
Immun. 70, 2640-2649.

Qi, M., Chi, M., Sun, X., Xie, X., Weir, M. D., Oates, T. W., et al., (2019). Novel nanomaterial-based antibacterial photodynamic therapies to combat oral bacterial biofilms and infectious diseases. Int. J. Nanomed. 14, 69376956.

Queller, D. C. (2000). Relatedness and the fraternal major transitions. Philos. Trans. R. Soc. B Biol. Sci. 355, 16471655. doi:10.1098/rstb.2000.0727

Rainey, P. B. and Rainey, K. (2003). Evolution of cooperation and conflict in experimental bacterial populations. $\begin{array}{lll}\text { Nature } & 425, & 72-74 .\end{array}$ doi:10.1038/nature01906

Ramage G, Martinez JP, Lopez-Ribot JL (2006) Candida biofilms on implanted biomaterials: a clinically significant problem.

Res 6:979-986

Romaní, A. M., (2010). "Freshwater biofilms," in Biofouling, eds J. C. Thomason and S. Dürr, (Oxford: WileyBlackwell), 137-153.

Romling U, Galperin MY, Gomelsky M. Cyclic di-GMP: the first 25 Years of a universal bacterial second messenger. Microbiol Mol Biol Rev 2013; 77:1-52.

Römling, U., Kjelleberg, S., Normark, S., Nyman, L., Uhlin, B. E., and Åkerlund, B. (2014). Microbial biofilm formation: a need to act. J. Intern. Med. 276, 98110.

Rout, B., Liu, C. H., and Wu, W. C. (2017). Photosensitizer in lipid nanoparticle: a nano-scaled approach to antibacterial function. Sci Rep. 7:7892.

Roy AB, Petrova OE, Sauer K. The phosphodiesterase DipA (PA5017) is essential for Pseudomonas aeruginosa biofilm dispersion. J Bacteriol 2012;194:2904-15.

Sampaio, J., Machado, D., Gomes, A. M., Machado, I., Santos, C., Lima, N., et al., 
(2016). Deciphering the contribution of biofilm to the pathogenesis of peritoneal dialysis infections: characterization and microbial behaviour on dialysis fluids. PLoS ONE 11:e0157870. doi: 10.1371/journal.pone.0157870.

Schachter, B. (2003). Slimy business-the biotechnology of biofilms. Nat. Biotechnol. 21, 361-365. doi: 10.1038/nbt0403-361.

Shrout, J.D., Tolker-Nielsen, T., Givskov, M., and Parsek, M.R. 2011. The contribution of cell-cell signaling and motility to bacterial biofilm formation. MRS Bull. 36, 367-373.

Silva, A. J., and Benitez, J. A. (2016). Vibrio cholerae Biofilms and Cholera Pathogenesis. PLoS Negl. Trop. Dis. 10:e0004330

Simon, M., Grossart, H. P., Schweitzer, B., and Ploug, H. (2002). Microbial ecology of organic aggregates in aquatic ecosystems. Aquat. Microb. Ecol. 28, 175-211. doi: 10.3354/ame028175

Singh PK Parsek MR Greenberg EP Welsh MJ (2002) A component of innate immunity prevents bacterial biofilm development. Nature417: 552-555.

SlíŽová, M., Nemcová, R., Mad'ar, M., Hadryová, J., Gancarcíková, S., and Popper, ` M., Pistl, J. (2015). Analysis of biofilm formation by intestinal lactobacilli. Can. J. Microbiol. 61, 437446.

Stewart, P. S., and Bjarnsholt, T. (2020). Risk factors for chronic biofilm-related infection associated with implanted medical devices. Clin. Microbiol. Infect. Stoodley P, Wilson S, Hall-Stoodley L, Boyle JD, Lappin-Scott HM, Costerton JW (2001). Growth and detachment of cell clusters from mature mixed-species biofilms. Appl Environ Microbiol 67:5608-5613.

Stoodley, P., Sauer, K., Davies, D. G., and Costerton, J. W. (2002). Biofilms as complex differentiated communities. Annu. Rev. Microbiol. 56, 187-209. doi:

10.1146/annurev.micro.56.012302.1607 05

Strassmann, J. E. and Queller, D. C. (2011). Evolution of cooperation and control of cheating in a social microbe. Proc. Natl. Acad. Sci. USA 108, 10855-10862. doi:10.1073/pnas.1102451108

Tascini, C., Sozio, E., Corte, L., Sbrana, F., Scarparo, C., Ripoli, A., et al., (2018). The role of biofilm forming on mortality in patients with candidemia: a study derived from real world data. Infect. Dis. (Lond). 50, 214-219. doi: 10.1080/23744235.2017.1384956

Tasia, W., Lei, C., Cao, Y., Ye, Q., He, Y., and $\mathrm{Xu}, \mathrm{C}$. (2020). Enhanced eradication of bacterial biofilms with DNase I-loaded silver-doped mesoporous silica nanoparticles. Nanoscale 12, 2328-2332.

Teschler, J. K., Zamorano-Sánchez, D., Utada, A. S., Warner, C. J. A., Wong, G. C. L., Linington, R. G., et al., (2015). Living in the matrix: assembly and control of Vibrio cholerae biofilms. Nat. Rev. Microbiol. 13, 255-268. doi: 10.1038/nrmicro3433 F

Tunney, M. M., and Gorman, S. P. (2002). Evaluation of a poly (vinyl pyrollidone)-coated biomaterial for urological use. Biomaterials 23, 46014608.

van Gestel, J., Weissing, F. J., Kuipers, O. P. and Kovács, A. T. (2014). Density of founder cells affects spatial pattern formation and cooperation in Bacillus subtilis biofilms. ISME J.8, 2069-2079.

Vos, M. and Velicer, G. J. (2009). Social conflict in centimeter-and global-scale populations of the bacterium Myxococcus xanthus. Curr. Biol. 19, 1763-1767.

doi:10.1016/j.cub.2009.08.061 
Walker, J. N., Pinkner, C. L., Lynch, A. J. L., Ortbal, S., Pinkner, J. S., Hultgren, S. J., et al., (2020). Deposition of host matrix proteins on breast implant surfaces facilitates Staphylococcus epidermidis biofilm formation: in vitro analysis. Aesthet. Surg. J. 40, 281-295.

Wei, Q. and Ma, L.Z. 2013. Biofilm matrix and its regulation in Pseudomonas aeruginosa. Int. J. Mol. Sci. 14, 20983 21005.

West, S. A., Griffi n, A. S. \& Gardner, A. (2007) Social semantics: altruism, cooperation, mutualism, strong reciprocity and group selection. Journal of Evolutionary Biology, 20, 415 -432.

Whitchurch, C.B., Tolker-Nielsen, T., Ragas, P.C., and Mattick, J.S. 2002. Extracellular DNA required for bacterial biofilm formation. Science 295, 1487.

Wilson S, Hamilton MA, Hamilton GC, Schumann MR, Stoodley P (2004). Statistical quantification of detachment rates and size distributions of cell clumps from wild-type (PAO1) and cell signaling mutant (JP1) Pseudomonas aeruginosa biofilms. Appl Environ Microbiol 70: 5847-5852.
Wimpenny, J., Manz, W., and Szewzyk, U. (2000). Heterogeneity in biofilms. FEMS Microbiol. Rev. 24, 661-671. doi: 6976.2000.tb00565.x E

Ymele-Leki P, Ross JM (2007). Erosion from Staphylococcus aureus biofilms grown under physiologically relevant fluid shear forces yields bacterial cells with reduced avidity to collagen. Appl Environ Microbiol 73:1834-1841.

Zahran, K. M., Agban, M. N., Ahmed, S. H., Hassan, E. A., and Sabet, M. A. (2015). Patterns of Candida biofilm on intrauterine devices. J. Med. Microbiol. 64(Pt 4):375-381. doi: 10.1099/jmm.0.000042

Zambori, C., Tirziu, E., Nichita, I., Cumpanasoiu, C., Gros, R., Seres, M., Mladin, B. and Mot, M. 2012.Biofilm Implication in Oral Diseases of Dogs and Cats. Anim. Sci. Biotechnol. 45(2): 208-212.

Zhou, H. M., Li, D. C., Wang, Y. Y., Zhu, H., $\mathrm{Su}, \mathrm{Y}$. Q., and Mao, Y. (2018). Antimicrobial peptide Pc-pis: a new cancer cell killer. Fish Shellfish Immunol. 81, 368-373.

\section{How to cite this article:}

Namita Shukla, Rajesh Kumar, Jubeda Begum and Garima Pandey. 2021. Biofilm Associated Infection and its Novel Therapeutics Strategy. Int.J.Curr.Microbiol.App.Sci. 10(02): 964-980. doi: https://doi.org/10.20546/ijcmas.2021.1002.115 